\title{
Mesenchymal stem cells for inducing tolerance in organ transplantation
}

\author{
Kequan Guo ${ }^{1 *}$, Susumu Ikehara ${ }^{2}$ and Xu Meng ${ }^{1}$ \\ ' Department of Cardiac Surgery, Beijing Institute of Heart Lung and Blood Vessel Disease, Beijing Anzhen Hospital affiliated to Capital Medical University, Beijing, \\ China \\ ${ }^{2}$ Department of Stem Cell Disorders, Kansai Medical University, Hirakata City, Japan
}

\section{Edited by:}

Daniele Bottai, University of Milan,

Italy

Reviewed by:

Ema Anastasiadou, Biomedical

Research Foundation Athens

Acaademy, Greece

Hannes Klump, University Hospital

Essen, Germany

Luke Boulter, University of

Edinburgh, UK

\section{*Correspondence:}

Kequan Guo, Department of Cardiac

Surgery, Beijing Institute of Heart Lung and Blood Vessel Disease,

Beijing Anzhen Hospital affiliated to Capital Medical University, No.2

Anzhen Road, Beijing 100029, China

e-mail:guokequan@hotmail.com
Organ transplantation is useful for treating the end stage of organ failure. The induction of tolerance to the transplanted organ is essential for its long-term survival. Immunologic tolerance can be induced by immunosuppressive agents and mixed chimerism. Mixed chimerism is a state in which both recipient-and donor-derived blood cells remain in the hematopoietic system after allogeneic hematopoietic stem cells have been transplanted. Mesenchymal stem cells (MSCs), and immune cells such as dendritic cells and T-reg cells play an important role in the induction of tolerance. MSCs secrete cytokines, which modulate the immune response. In particular, they upregulate T-reg cell function and thereby induce tolerance. Intra-bone marrow-bone marrow transplantation recruits both donor-derived HSCs and MSCs, inducing persistent donor-specific tolerance without the use of immunosuppressants. In this review, we summarize the use of MSCs to induce tolerance in organ transplantation.

Keywords: tolerance, mesenchymal stem cells, organ transplantation, mixed chimerism, bone marrow transplantation

\section{INTRODUCTION}

Organ transplantation is useful for treating the end stage of organ failure, but it is imperative that stable tolerance is induced in the recipients in order for the transplanted organ to survive long term. The induction of immunological tolerance to organ transplants can be categorized into the use of immunosuppressive agents to modulate $\mathrm{T}$ cell and $\mathrm{B}$ cell agents and the use of cellular therapies such as mixed chimerism (Salisbury et al., 2013). Immunosuppressive agents have been used to prevent an immune response in the host and the acute rejection of the transplanted organ. However, the side effects of non-specific immunosuppressive agents include not only the risk of infection but also the inability to prevent the chronic rejection of the transplanted organ (Ildstad et al., 2011). Mixed chimerism, which can be established by the transplantation of hematopoietic stem cells (HSCs), has been shown to be a better method of inducing tolerance in organ transplantation. In clinical practice, organ transplantation using a conditioning regimen consisting of total lymphoid irradiation plus immunosuppressants such as cyclophosphamide (CYP) and fludarabine has been shown to induce mixed chimerism (Sachs et al., 2014). One case report describes how a patient who received $\mathrm{CD} 34+$ cells $\left(8 \times 10^{6} / \mathrm{kg}\right.$ body weight) on day14 after kidney transplantation, showed neither kidney rejection nor clinical manifestations of graftversus-host disease (GVHD) during a follow-up for of more than 2 years (Scandling et al., 2008). Another review summarizes the induction of long-term allograft tolerance through mixed chimerism in small and large animal models, and includes clinical studies (Sachs et al., 2011). Allogeneic chimerism and tolerance have been induced by HSC transplantation in human leukocyte antigen-mismatched patients when kidneys were transplantedwithout any evidence of acute GVHD in the recipients. And stable renal function was maintained as a result of the persistent donor chimerism without the use of immunosuppressive agents (Leventhal et al., 2012). Immune cells such as regulatory T (T-reg) cells, immature dendritic cells (DCs), and mesenchymal stem cells (MSCs) play important roles in the induction of immune tolerance in organ transplantation (Wood et al., 2012). Recent reports have suggested that MSC-derived-exosomes, which are released by exocytosis with the plasma membrane, may benefit therapy-refractory GvHD patients. The use of MSC exosomes, being-the therapeutically active component of MSCs, provides a number of advantages compared to just MSCs (Kordelas et al., 2014).

\section{IMMUNE TOLERANCE}

Immune tolerance includes central tolerance, which occurs in the thymus, and peripheral tolerance, which includes the deletion of effector $\mathrm{T}$ cells and the induction of expansion of active T-reg cells (Wood and Sakaguchi, 2003). In central tolerance, T cell precursors from the bone marrow (BM) enter the thymus and are selected by thymic epithelial cells via positive and negative selection. These selected $\mathrm{T}$ cells show tolerance to autoantigens when they enter peripheral lymphoid tissues. Peripheral tolerance includes the induction of anergy, and the active regulation of effector T cells. Immature DCs, T reg cells and MSCs play an important role in the induction of peripheral tolerance. BM-derived immature DCs express low MHC class II and co-stimulatory molecules to promote tolerance to solid organ allografts, and the injection of donor-derived DCs may prevent 
the rejection of MHC-mismatched skin grafts (Roelen et al., 2003; van Kooten et al., 2011).

The markers of T-reg cells, CD4, CD25, and FoxP3, mainly mature in the thymus. The presence of T-reg cells has been reported to reduce the need for conditioning regimens in the generation of mixed chimerism (Raimondi et al., 2010),being the presence of both donor- and recipient-derived hematopoietic cells in the recipients after BM transplantation (BMT) (Pilat and Wekerle, 2010). It has been shown that mixed chimerism is more effective than full chimerism in combating infectious risk when allogeneic kidney transplants were performed in humans, with non-myeloablative conditioning promoting the mixed chimerism and helping the renal allografts to survive (Buhler et al., 2002; Kawai et al., 2011). MSCs can be isolated from many tissues, and not only support the growth of hematopoietic stem cells (HSCs), but also secrete cytokines to regulate the immune response. Human MSCs promote the generation of CD4+CD25+FoxP3+T-reg cells, and induce tolerance to allografts (Casiraghi et al., 2008; English et al., 2009). Moreover, MSCs secrete matrix metalloproteinases (MMP), protect allogeneic islets, and maintain long-term normoglycemia through MMP-2 and -9 in vitro (Ding et al., 2009).

\section{MSCs INDUCE TOLERANCE IN ORGAN TRANSPLANTATION}

The functions of MSCs and their effects on immune cells have been summarized in two reviews (Uccelli et al., 2008; Li and Ikehara, 2013). MSCs suppress allogeneic T cell responses by secreting soluble factors such as PGE2, IL-10, and IL-6 (English, 2013), and modulate DC function, indirectly regulate $\mathrm{T}$ and $\mathrm{B}$ cell activity, delay and prevent the development of GVHD and suppress DC function (Zhang et al., 2009; Aldinucci et al., 2010). MSCs have been shown to alter the NK cell phenotype and suppress proliferation, decrease cytokine levels such as those of TNF $\alpha$, IFN $\gamma$ and IL-12, and increase IL-10. One report has shown that porcine MSCs inhibit alloreactive T cells through the induction of PGE2 and indoleamine 2,3-dioxygenase (IDO) (Hsu et al., 2013).

The immunoregulatory properties of MSCs have been reported in vitro and in vivo. MSCs suppress T-cell responses, inducing tolerance to transplanted kidney via the expression of IDO (Ge et al., 2010). An infusion of MSCs and rapamycin has been shown to induce heart allograft-specific tolerance, supporting the idea that MSCs might be used for inducing tolerance in a clinical setting (Ge et al., 2009). The MSC infusion leads to an expansion of T-reg cells and prolongs allograft survival in a MHC matched heterotopic heart transplantation model. Moreover, MSC infusion is characterized by reduced numbers of Th1 effector cells (Casiraghi et al., 2008). However, there is one report indicating that donor-specific MSC pre-treatment resulted in a higher degree of kidney cortex tissue damage and elevated creatinine levels in a rat kidney transplantation model (Seifert et al., 2012). Another report showed that MSCs suppressed allogeneic $\mathrm{T}$-cell responses and prolonged the survival of transplanted hearts by improving the Th1/Th2 balance when allogeneic heart transplantation was combined with the intravenous infusion of MSCs (Zhou et al., 2006). Transplanted MSCs may promote revascularization and improve islet graft function after the co-transplantation of islets with MSCs in streptozotocininduced diabetic rats (Ito et al., 2010).

In clinical trials, intravenous infusions of autologous BMderived MSCs were given to kidney allograft recipients. Although immunosuppression remained unaltered, there was a resolution of tubulitis without interstitial fibrosis/tubular atrophy in one third of patients. Additionally, five of the six patients displayed a donor-specific downregulation of peripheral blood mononuclear cell proliferation, which was not reported in patients that did not have the MSC treatment. These results suggest that autologous BM-derived MSC treatment provides systemic immunosuppression in allograft transplantation (Reinders et al., 2013). Calcineurin inhibitors (CNIs) have been reported to reduce acute rejection rates in kidney recipients. The infusion of MSCs combined with CNIs improved renal function such as the estimated glomerular filtration rate at the first month after treatment. This therapy decreased the incidence of acute rejection, and also decreased the risk of opportunistic infection at 1 year after treatment (Tan et al., 2012). Infusion of MSCs was used for the treatment of patients who received kidney transplants, and these infused MSCs increased the percentage of CD4+CD25+FoxP3+CD127- T-reg cells and decreased memory $\mathrm{T}$ cells, and CD8+ T cell activity. The infusion of MSCs thus appears to be a safe and clinically feasible method for patients receiving organ transplants (Perico et al., 2011). BM-derived MSCs have been used clinically to treat GVHD, decrease the risk of infection, and help induce tolerance in organ transplantation, and one review indicates that MSCs promote tolerance in the case of kidney transplants (Casiraghi et al., 2014).

When MSCs are infused by intravenous injection, they become trapped in the lungs and other tissues, and it is therefore preferable for the MSCs to be directly injected into the bone cavity. Intra-bone marrow-BMT (IBM-BMT) has been shown to efficiently recruit not only donor-derived HSCs but also MSCs in animal experiments (Fukui et al., 2007; Guo et al., 2008; Song et al., 2008). Furthermore, IBM-BMT induced tolerance to adult allogeneic liver in mice (Okazaki et al., 2008). IBM-BMT is a feasible strategy for the induction of persistent donor-specific tolerance, enables the use of reduced radiation doses as conditioning

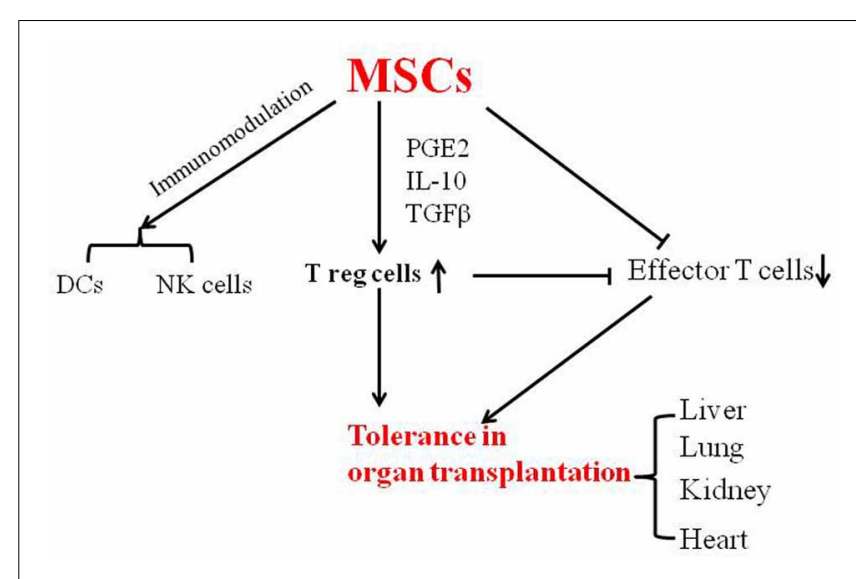

FIGURE 1 | MSCs induce tolerance in organ transplantation. 
regimens, and obviates the need for immunosuppressants (Guo et al., 2008). IBM-BMT induced tolerance in the case of allogeneic lung transplants, while intravenous BMT failed to do so (Kaneda et al., 2005). HSCs can normally proliferate in major histocompatibility complex (MHC)-compatible MSCs even in allogeneic microenvironments.

In conclusion, MSCs have been shown to prevent GVHD, and to induce tolerance in organ transplantation in both animal and clinical studies (Figure 1). MSCs can be easily isolated from bone marrow and adipose tissue, and their use thus represents a feasible approach in the clinical setting for inducing tolerance in organ transplantation.

\section{ACKNOWLEDGMENTS}

We would like to thank Mr. Hilary Eastwick-Field and Ms. Keiko Ando for their help in the preparation of the manuscript. This work was supported by a grant from the National Natural Science of Foundation of China (81100177).

\section{REFERENCES}

Aldinucci, A., Rizzetto, L., Pieri, L., Nosi, D., Romagnoli, P., Biagioli, T., et al. (2010). Inhibition of immune synapse by altered dendritic cell actin distribution: a new pathway of mesenchymal stem cell immune regulation. J. Immunol. 185, 5102-5110. doi: 10.4049/jimmunol.1001332

Buhler, L. H., Spitzer, T. R., Sykes, M., Sachs, D. H., Delmonico, F. L., TolkoffRubin, N., et al. (2002). Induction of kidney allograft tolerance after transient lymphohematopoietic chimerism in patients with multiple myeloma and end-stage renal disease. Transplantation 74, 1405-1409. doi: 10.1097/00007890200211270-00011

Casiraghi, F., Azzollini, N., Cassis, P., Imberti, B., Morigi, M., Cugini, D., et al. (2008). Pretransplant infusion of mesenchymal stem cells prolongs the survival of a semiallogeneic heart transplant through the generation of regulatory $\mathrm{T}$ cells. J. Immunol. 181, 3933-3946.

Casiraghi, F., Remuzzi, G., and Perico, N. (2014). Mesenchymal stromal cells to promote kidney transplantation tolerance. Curr. Opin. Organ Transplant. 19, 47-53. doi: 10.1097/MOT.0000000000000035

Ding, Y., Xu, D., Feng, G., Bushell, A., Muschel, R. J., and Wood, K. J. (2009). Mesenchymal stem cells prevent the rejection of fully allogenic islet grafts by the immunosuppressive activity of matrix metalloproteinase- 2 and -9 . Diabetes 58, 1797-1806. doi: 10.2337/db09-0317

English, K. (2013). Mechanisms of mesenchymal stromal cell immunomodulation. Immunol. Cell Biol. 91, 19-26. doi: 10.1038/icb.2012.56

English, K., Ryan, J. M., Tobin, L., Murphy, M. J., Barry, F. P., and Mahon, B. P. (2009). Cell contact, prostaglandin $\mathrm{E}(2)$ and transforming growth factor beta 1 play non-redundant roles in human mesenchymal stem cell induction of CD4+CD25(High) forkhead box P3+ regulatory T cells. Clin. Exp. Immunol. 156, 149-160. doi: 10.1111/j.1365-2249.2009.03874.x

Fukui, J., Inaba, M., Ueda, Y., Miyake, T., Hosaka, N., Kwon, A. H., et al. (2007). Prevention of graft-versus-host disease by intra-bone marrow injection of donor T cells. Stem Cells 25, 1595-1601. doi: 10.1634/stemcells.2006-0234

Ge, W., Jiang, J., Arp, J., Liu, W., Garcia, B., and Wang, H. (2010). Regulatory Tcell generation and kidney allograft tolerance induced by mesenchymal stem cells associated with indoleamine 2,3-dioxygenase expression. Transplantation 90, 1312-1320. doi: 10.1097/TP.0b013e3181fed001

Ge, W., Jiang, J., Baroja, M. L., Arp, J., Zassoko, R., Liu, W., et al. (2009). Infusion of mesenchymal stem cells and rapamycin synergize to attenuate alloimmune responses and promote cardiac allograft tolerance. Am. J. Transplant. 9, 1760-1772. doi: 10.1111/j.1600-6143.2009.02721.x

Guo, K., Inaba, M., Li, M., An, J., Cui, W., Song, C., et al. (2008). Longterm donor-specific tolerance in rat cardiac allografts by intrabone marrow injection of donor bone marrow cells. Transplantation 85, 93-101. doi: 10.1097/01.tp.0000296061.71662.76

Hsu, W. T., Lin, C. H., Chiang, B. L., Jui, H. Y., Wu, K. K., and Lee, C. M. (2013). Prostaglandin E2 potentiates mesenchymal stem cell-induced IL-10+IFN-gamma+CD4+ regulatory T cells to control transplant arteriosclerosis. J. Immunol. 190, 2372-2380. doi: 10.4049/jimmunol.1202996
Ildstad, S. T., Shirwan, H., and Leventhal, J. (2011). Is durable macrochimerism key to achieving clinical transplantation tolerance? Curr. Opin. Organ Transplant. 16, 343-344. doi: 10.1097/MOT.0b013e328348e67a

Ito, T., Itakura, S., Todorov, I., Rawson, J., Asari, S., Shintaku, J., et al. (2010). Mesenchymal stem cell and islet co-transplantation promotes graft revascularization and function. Transplantation 89, 1438-1445. doi: 10.1097/TP.0b013e3181db09c4

Kaneda, H., Adachi, Y., Saito, Y., Ikebukuro, K., Machida, H., Suzuki, Y., et al. (2005). Long-term observation after simultaneous lung and intra-bone marrow-bone marrow transplantation. J. Heart Lung Transplant. 24, 1415-1423. doi: 10.1016/j.healun.2004.08.015

Kawai, T., Cosimi, A. B., and Sachs, D. H. (2011). Preclinical and clinical studies on the induction of renal allograft tolerance through transient mixed chimerism. Curr. Opin. Organ Transplant. 16, 366-371. doi: 10.1097/MOT.0b013e3283484b2c

Kordelas, L., Rebmann, V., Ludwig, A. K., Radtke, S., Ruesing, J., Doeppner, T. R., et al. (2014). MSC-derived exosomes: a novel tool to treat therapy-refractory graft-versus-host disease. Leukemia. doi: 10.1038/leu.2014.41. [Epub ahead of print].

Leventhal, J., Abecassis, M., Miller, J., Gallon, L., Ravindra, K., Tollerud, D. J., et al. (2012). Chimerism and tolerance without GVHD or engraftment syndrome in HLA-mismatched combined kidney and hematopoietic stem cell transplantation. Sci. Transl. Med. 4, 124ra28. doi: 10.1126/scitranslmed.3003509

Li, M., and Ikehara, S. (2013). Bone-marrow-derived mesenchymal stem cells for organ repair. Stem Cells Int. 2013, 132642. doi: 10.1155/2013/132642

Okazaki, S., Hisha, H., Mizokami, T., Takaki, T., Wang, X., Song, C., et al. (2008). Successful acceptance of adult liver allografts by intra-bone marrow-bone marrow transplantation. Stem Cells Dev. 17, 629-639. doi: 10.1089/scd.2007.0218

Perico, N., Casiraghi, F., Introna, M., Gotti, E., Todeschini, M., Cavinato, R. A., et al. (2011). Autologous mesenchymal stromal cells and kidney transplantation: a pilot study of safety and clinical feasibility. Clin. J. Am. Soc. Nephrol. 6, 412-422. doi: 10.2215/CJN.04950610

Pilat, N., and Wekerle, T. (2010). Transplantation tolerance through mixed chimerism. Nat. Rev. Nephrol. 6, 594-605. doi: 10.1038/nrneph.2010.110

Raimondi, G., Sumpter, T. L., Matta, B. M., Pillai, M., Corbitt, N., Vodovotz, Y., et al. (2010). Mammalian target of rapamycin inhibition and alloantigenspecific regulatory $\mathrm{T}$ cells synergize to promote long-term graft survival in immunocompetent recipients. J. Immunol. 184, 624-636. doi: 10.4049/jimmunol.0900936

Reinders, M. E., de Fijter, J. W., Roelofs, H., Bajema, I. M., de Vries, D. K., Schaapherder, A. F., et al. (2013). Autologous bone marrow-derived mesenchymal stromal cells for the treatment of allograft rejection after renal transplantation: results of a phase I study. Stem Cells Transl. Med. 2, 107-111. doi: 10.5966/sctm.2012-0114

Roelen, D. L., Schuurhuis, D. H., van den Boogaardt, D. E., Koekkoek, K., van Miert, P. P., van Schip, J. J., et al. (2003). Prolongation of skin graft survival by modulation of the alloimmune response with alternatively activated dendritic cells. Transplantation 76, 1608-1615. doi: 10.1097/01.TP.0000086340.30817.BA

Sachs, D. H., Kawai, T., and Sykes, M. (2014). Induction of tolerance through mixed chimerism. Cold Spring Harb. Perspect. Med. 4, a015529. doi: 10.1101/cshperspect.a015529

Sachs, D. H., Sykes, M., Kawai, T., and Cosimi, A. B. (2011). Immuno-intervention for the induction of transplantation tolerance through mixed chimerism. Semin. Immunol. 23, 165-173. doi: 10.1016/j.smim.2011.07.001. [Epub ahead of print].

Salisbury, E. M., Game, D. S., and Lechler, R. I. (2013). Transplantation tolerance. Pediatr. Nephrol. doi: 10.1007/s00467-013-2659-5

Scandling, J. D., Busque, S., Dejbakhsh-Jones, S., Benike, C., Millan, M. T., Shizuru, J. A., et al. (2008). Tolerance and chimerism after renal and hematopoietic-cell transplantation. N. Engl. J. Med. 358, 362-368. doi: 10.1056/NEJMoa074191

Seifert, M., Stolk, M., Polenz, D., and Volk, H. D. (2012). Detrimental effects of rat mesenchymal stromal cell pre-treatment in a model of acute kidney rejection. Front. Immunol. 3:202. doi: 10.3389/fimmu.2012.00202

Song, C., Hisha, H., Wang, X., Li, Q., Li, M., Cui, W., et al. (2008). Facilitation of hematopoietic recovery by bone grafts with intra-bone marrow-bone marrow transplantation. Immunobiology 213, 455-468. doi: 10.1016/j.imbio.2007.10.015

Tan, J., Wu, W., Xu, X., Liao, L., Zheng, F., Messinger, S., et al. (2012). Induction therapy with autologous mesenchymal stem cells in living-related kidney transplants: a randomized controlled trial. JAMA 307, 1169-1177. doi: 10.1001/jama.2012.316 
Uccelli, A., Moretta, L., and Pistoia, V. (2008). Mesenchymal stem cells in health and disease. Nat. Rev. Immunol. 8, 726-736. doi: 10.1038/nri2395

van Kooten, C., Lombardi, G., Gelderman, K. A., Sagoo, P., Buckland, M., Lechler, R., et al. (2011). Dendritic cells as a tool to induce transplantation tolerance: obstacles and opportunities. Transplantation 91, 2-7. doi: 10.1097/TP.0b013e31820263b3

Wood, K. J., Bushell, A., and Hester, J. (2012). Regulatory immune cells in transplantation. Nat. Rev. Immunol. 12, 417-430. doi: 10.1038/nri3227

Wood, K. J., and Sakaguchi, S. (2003). Regulatory T cells in transplantation tolerance. Nat. Rev. Immunol. 3, 199-210. doi: 10.1038/nri1027

Zhang, B., Liu, R., Shi, D., Liu, X., Chen, Y., Dou, X., et al. (2009). Mesenchymal stem cells induce mature dendritic cells into a novel Jagged-2-dependent regulatory dendritic cell population. Blood 113, 46-57. doi: 10.1182/blood-2008-04154138

Zhou, H. P., Yi, D. H., Yu, S. Q., Sun, G. C., Cui, Q., Zhu, H. L., et al. (2006). Administration of donor-derived mesenchymal stem cells can prolong the survival of rat cardiac allograft. Transplant. Proc. 38, 3046-3051. doi: 10.1016/j.transproceed.2006.10.002
Conflict of Interest Statement: The authors declare that the research was conducted in the absence of any commercial or financial relationships that could be construed as a potential conflict of interest.

Received: 09 January 2014; accepted: 28 February 2014; published online: 17 March 2014.

Citation: Guo K, Ikehara S and Meng X (2014) Mesenchymal stem cells for inducing tolerance in organ transplantation. Front. Cell Dev. Biol. 2:8. doi: 10.3389/fcell. 2014.00008

This article was submitted to Stem Cell Treatments, a section of the journal Frontiers in Cell and Developmental Biology.

Copyright (c) 2014 Guo, Ikehara and Meng. This is an open-access article distributed under the terms of the Creative Commons Attribution License (CC BY).

The use, distribution or reproduction in other forums is permitted, provided the original author(s) or licensor are credited and that the original publication in this journal is cited, in accordance with accepted academic practice. No use, distribution or reproduction is permitted which does not comply with these terms. 